\title{
EXPOSIÇÃO A RISCOS DOS PROFISSIONAIS DA ENFERMAGEM DO SERVIÇO DE ATENDIMENTO MÓVEL DE URGÊNCIA (SAMU)
}

\section{ARTIGO DE REVISÃO}

PAULA, Michelly Rodrigues de ${ }^{1}$

SANTOS, Keily dos ${ }^{2}$

BATISTA, Marcos Antonio Silva ${ }^{3}$

GONÇALVES, Rosane Cristina Mendes ${ }^{4}$

REIS, Suely da Silva ${ }^{5}$

PAULA, Michelly Rodrigues de. Et al. Exposição a riscos dos profissionais da enfermagem do serviço de atendimento móvel de urgência (SAMU). Revista Científica Multidisciplinar Núcleo do Conhecimento. Ano 05, Ed. 12, Vol. 11, pp. 8491. Dezembro de 2020. ISSN: 2448-0959, Link de acesso: https://www.nucleodoconhecimento.com.br/saude/exposicao-a-riscos, DOI: 10.32749/nucleodoconhecimento.com.br/saude/exposicao-a-riscos

\section{RESUMO}

O Atendimento Pré-Hospitalar (APH) desenvolve um sistema de atendimento às urgências e emergências de caráter privado e público. O Serviço de Atendimento Móvel de Urgência (SAMU) é composto por uma equipe multiprofissional integrada,

\footnotetext{
${ }^{1}$ Graduada em Enfermagem pelo Centro Universitário Luterano de Palmas.

${ }^{2}$ Graduada em Enfermagem pelo Centro Universitário Luterano de Palmas.

${ }^{3}$ Especialista em Enfermagem do Trabalho pela Faculdade Gianna Bereta.

${ }^{4}$ Exposição a riscos dos profissionais da enfermagem do serviço

${ }^{5}$ Graduada em Enfermagem pelo Centro Universitário Luterano de Palmas.
} 
cujas possibilidades de recuperação do paciente estão relacionadas com a rapidez e eficiência dos serviços prestados. O objetivo do estudo foi: verificar na literatura os riscos aos quais os trabalhadores de enfermagem são expostos. Adotou-se a pesquisa documental e revisão bibliográfica, com artigos publicados no período de 2004 a 2014. Através dos resultados obtidos verificou-se que os fatores de riscos ocupacionais estão presentes diariamente nas atividades realizadas pelos profissionais de saúde, cabendo aos gestores e aos profissionais em geral, a realização da avaliação dos riscos de forma a minimizar possíveis impactos sobre a saúde do trabalhador. Os diversos tipos de riscos laborais aos quais estão expostos os profissionais do APH como físicos, químicos, biológicos, ergonômicos e psicossociais, mecânicos e de acidente, predispõem a acidentes e enfermidades ocupacionais, fazendo-se necessário identificar no ambiente de trabalho os riscos existentes, para a prevenção desses agravos. Ações de educação permanente e a promoção da prática de atividade física são algumas das estratégias utilizadas para lidar como os riscos aos quais são expostos. Desta forma, compreender os riscos ocupacionais que podem afetar o trabalhador é de suma importância para promover a prevenção e/ou diminuição dos riscos inseridos no processo e ambiente de trabalho. Sugerem-se políticas de controle e prevenção de riscos ocupacionais voltados especificamente para o bem-estar dos profissionais do SAMU.

Palavras-chave: Exposição a Riscos, Profissionais de Enfermagem, SAMU.

\section{INTRODUÇÃO}

O Atendimento Pré-Hospitalar (APH) no Brasil foi executado pelos estados, que desenvolveram um sistema de atendimento às urgências e emergências de caráter privado ou público, no qual em seu início histórico predominantemente era executado pelo Corpo de Bombeiros Militares (MARTINS; PRADO, 2003). No entanto, a atividade enfrentou grandes dificuldades até meados da década de 90 , devido à falta de uma legislação específica que contribuísse para a sustentação de uma estrutura de APH. A partir de 1999, o Ministério da Saúde (MS) vem publicando portarias a fim de regulamentar e normatizar este tipo de atendimento em todo o Brasil, através de uma 
Política Nacional baseada nas diretrizes do Sistema Único de Saúde (SUS), organizado por regiões e considerando o atendimento hierarquizado.

O Serviço de Atendimento Móvel de Urgência (SAMU) é composto por uma equipe multiprofissional integrada e preparada para refletir positivamente sobre o paciente, uma vez que as possibilidades de sua recuperação estão diretamente relacionadas com a rapidez e eficiência dos serviços prestados na urgência (CAMPOS; FARIAS; RAMOS, 2009).

Segundo Pereira; Lima (2009) na prática cotidiana dos serviços de Atendimento PréHospitalar, o trabalho se estrutura a partir de instrumentos tecnológicos e do estabelecimento de relações entre os atores, especialmente no atendimento à vítima de acidentes de trânsito, quando várias áreas se envolvem nessa assistência. $\mathrm{O}$ trabalho desenvolvido caracteriza-se de forma coletiva, cujo resultado depende dos atos de cada um desses atores, que atuam de acordo com seus saberes e práticas específicas, e por todos eles no seu conjunto. As ações são desenvolvidas por vários profissionais, respeitadas as especificidades, competências e responsabilidade de cada membro da equipe.

São Paulo foi um dos primeiros estados a utilizar o $\mathrm{APH}$, tendo obtido maior impulso em 1989, após ser instituído oficialmente o SAMU - RESGATE, através de uma ação conjunta entre a Secretaria Estadual de Saúde (SES) e a Secretaria de Segurança Pública (SSP) - Corpo de Bombeiros. Gradativamente ao longo da década de 90 outros Estados Brasileiros foram implantando seus serviços de APH, sempre em parceria com Corpo de Bombeiros (SÃO PAULO, 2001).

$O$ atendimento realizado pelo SAMU tem por finalidade, prestar socorro à população em casos de urgência-emergência. Entre os agravos à saúde estão inclusos a violência ou quadros clínicos agudos, que são problemas de saúde pública que causam grande impacto na morbimortalidade da população (BRASIL, 2002). 
O SAMU funciona através do número de telefone 192, e atualmente conta com serviços de atendimento em várias cidades e capitais brasileiras. Seu atendimento é 24 horas por dia, com equipes formadas por profissionais como: médicos, enfermeiros, técnicos e auxiliares de enfermagem e motorista, que atendem às urgências traumáticas, clínicas, pediátricas, cirúrgicas, ginéco-obstétrica e saúde mental da população (SANTANA et al., 2012).

SAMU funciona através do número de telefone 192, e atualmente conta com serviços de atendimento em várias cidades e capitais brasileiras. Seu atendimento é 24 horas por dia, com equipes formadas por profissionais como: médicos, enfermeiros, técnicos em enfermagem e motorista, que atendem às urgências traumáticas, clínicas, pediátricas, cirúrgicas, ginéco-obstétrica e saúde mental da população (SANTANA et al., 2012).

Em 2001, o Ministério da Saúde instituiu a Política Nacional de Redução da Morbimortalidade por Acidentes e Violências que estabelecem diretrizes e responsabilidades institucionais, nas quais estão contempladas e valorizadas medidas de promoção da saúde e à prevenção desses eventos, por meio de ações estabelecidas em diferentes seguimentos sociais (BRASIL, 2001).

Diante disso, o $\mathrm{APH}$ móvel faz parte do sistema de assistência às urgências/emergências, constituindo-se um tipo de serviço de saúde recente no Brasil. Caracterizado por prestar assistência às pessoas em situações de agravos no local aonde tenha ocorrido o fato, garantindo atendimento precoce e adequado, este tipo de atendimento também é um mediador, sendo porta de entrada ao Sistema Único de Saúde (PEREIRA; LIMA, 2009).

\section{METODOLOGIA}

Adota-se neste estudo a pesquisa documental e revisão bibliográfica impressa e virtual. 
Segundo Prodanov; Freitas (2013), a revisão bibliográfica é uma pesquisa elaborada a partir de material já publicado sejam por livros, jornais, monografias, teses, dissertações entre outros, com a intenção de provar tal fato em material já descrito.

Para realização deste estudo foram utilizadas fontes de pesquisa eletrônicas tais como Scientific Eletronic Library Online (SCIELO) e o Google acadêmico, e livros afins. Considera-se para este estudo os artigos publicados no intervalo de tempo de 2006 a 2014 com as seguintes descrições: exposição a riscos, profissionais de enfermagem, Serviço de Atendimento Móvel de Urgência. Foram inclusos que tratam do tema proposto e excluídos artigos publicados em outra época e que não tratam do tema proposto.

\section{RESULTADOS E DISCUSSÕES}

Segundo Almeida et al. (2014), há uma multiplicidade de riscos ocupacionais, sendo os riscos de acidente de trânsito (causados principalmente pela alta velocidade, excesso de horas ao volante, rodovias mal conservadas e mal sinalizadas), os que apresentaram maior incidência, seguido dos riscos biológicos (responsáveis por infecções agudas e crônicas, causadas por vírus, fungos e bactérias), riscos ergonômicos (causados principalmente por uma postura irregular em situações como movimentação de pacientes, flexões de coluna, entre outros), riscos físicos (ocasionados pelas vibrações, ruídos, radiações, temperatura ambiental, iluminação e eletricidade), já os riscos químicos (acarretados pelo manejo de uma variedade de substâncias químicas e também por administração de medicamentos que podem ocasionar desde simples alergias, até importantes neoplasias) foram os riscos que apresentaram menor incidência.

Em estudos realizados por Oenning et al. (2012), os riscos de maior relevância foram os biológicos, seguido de acidente de trânsito, violência urbana e risco psicossocial relacionado à tensão emocional. Gomes; Santos (2012), reforçam em seus estudos que os trabalhadores estão suscetíveis a todos os tipos de riscos, porém, os acidentes biológicos ganham maior destaque devido ao tipo de atendimento. 
Tripple et al. (2013), afirmam que os riscos biológicos são os que mais expõe os trabalhadores e que está relacionado ao mau uso ou uso incorreto dos EPI's.

Em relação aos riscos ergonômicos Lúcio; Torres; Gusmão (2013), ressaltam que os problemas de saúde envolvendo os profissionais do SAMU tem aumentado e que o conhecimento sobre $\mathrm{o}$ assunto e adequações necessárias ao ambiente de trabalho, diminuiriam os problemas de saúde. SILVA et al. (2013a), complementam que a postura inadequada e os movimentos repetitivos favorecem a exposição aos riscos ergonômicos.

Guimarães et al. (2011), ressaltam que apesar da maioria dos profissionais conhecerem os riscos ocupacionais aos quais estão vulneráveis, os riscos biológicos são os mais perceptíveis entre os trabalhadores, no entanto, não levam em conta a importância dos demais riscos: físicos, químicos, mecânicos de acidentes e principalmente os ergonômicos. Segundo Costa; Sepúlvida (2013), apesar de terem conhecimento sobre os EPl's, os profissionais de enfermagem não fazem o uso, para tanto é necessário que haja uma educação em saúde eficaz que assegure a proteção dos trabalhadores, bem como dos pacientes.

De acordo com Guimarães et al. (2011), o ambiente de trabalho no qual os profissionais do SAMU estão expostos é potencialmente vulnerável à exposição aos agentes microbiológicos, acidentes de trânsito que envolvem ambulâncias (associado ao sono, alta velocidade, condições das rodovias), condições inadequadas de trabalho, violência urbana e sobrecarga de trabalho. De acordo com Silva et al., (2013b), a maioria dos trabalhadores de enfermagem são obrigados a optar por mais de um emprego, fatores desencadeantes para o estresse, gerando um desgaste excessivo do organismo, comprometendo a saúde física e mental.

Segundo Oliveira; Lopes; Paiva (2009), os acidentes com material biológico são os mais frequentes, quando associados com materiais perfurocortantes e/ou contato com fluídos corporais. Esses acidentes possuem alto risco de contaminação pelo vírus HIV e Hepatite, sendo necessário o acompanhamento sorológico por um ano, pois, 
somente ele poderá evidenciar a soro conversão. Ainda de acordo com Almeida et al. (2014), os riscos de acidente têm maior incidência entre os profissionais do Serviço de Atendimento Móvel de Urgência (SAMU), diferindo-se dos outros estudos que apontam os riscos biológicos com maior prevalência.

Há ainda a exposição à violência urbana (xingamentos, agressões físicas e verbais), causadas por pacientes e comunidade, principalmente em localidades violentas, além daqueles riscos ocupacionais específicos de categoria ocupacional (ZAPPAROLI; MARZIALE, 2006).

\section{CONSIDERAÇÕES FINAIS}

Os fatores de riscos ocupacionais estão presentes diariamente nas atividades realizadas pelos profissionais de saúde, cabendo aos gestores e aos profissionais em geral, a realização da avaliação dos riscos de forma a minimizar possíveis impactos sobre a saúde do trabalhador. Os diversos tipos de riscos laborais aos quais estão expostos os profissionais do APH como físicos, químicos, biológicos, ergonômicos e psicossociais, mecânicos e de acidente, predispõem a acidentes e enfermidades ocupacionais, fazendo-se necessário identificar no ambiente de trabalho os riscos existentes, para a prevenção desses agravos.

Apesar de alguns autores ressaltarem a importância dos agravos causados pelos riscos ergonômicos, os riscos biológicos são os mais percebidos pelos profissionais de saúde, tornando-se necessárias medidas preventivas e programas de educação continuada, abordando os demais riscos ocupacionais aos quais estão expostos, cujo sucesso está diretamente ligado à participação da equipe e o apoio da instituição no incentivo e na fiscalização.

Para reduzir os riscos ocupacionais é necessário estimular o uso de EPI's, adequação a jornada de trabalho, induzir a prática de ginástica laboral e atividades físicas, bem como, proporcionar um acompanhamento psicológico para aliviar a carga mental e estresse vivido pelos profissionais de saúde, estimulando uma visão de saúde integral, 
propondo uma nova prática de atenção à saúde do trabalhador, considerando a importância do cuidado, propiciando uma melhor condição física e mental, favorecendo assim, seu melhor desempenho.

Desta forma, compreender os riscos ocupacionais que podem afetar o trabalhador é de suma importância para promover a prevenção e/ou diminuição dos riscos inseridos no processo e ambiente de trabalho. Diante do exposto, sugere-se a implantação de programas de educação permanente, visando minimizar a ocorrência de acidentes ocupacionais, bem como a elaboração de estratégias de prevenção e controle, priorizando e estabelecendo políticas voltadas especificamente para o bem-estar dos profissionais do SAMU.

\section{REFERÊNCIAS}

ALMEIDA, Willian Alburquerque de et al. Riscos ocupacionais da equipe de enfermagem no Atendimento Pré-hospitalar móvel no município de Tangará da Serra - MT. III Online Conference - Management, Education and Health Promotion. Convibra Health. November $19-22,2014$.

BRASIL. Ministério da Saúde. Portaria GM/MS no 737 de 16 de maio de 2001. Política nacional de redução da morbimortalidade por acidentes e violências. BrasíliaDF, 2001.

Ministério da Saúde. Portaria no 2.048/GM, de 5 de novembro de 2002. Institui o Regulamento Técnico dos Sistemas Estaduais de Urgência e Emergência. Brasília-DF, 2002.

. Ministério do Trabalho e Emprego. Portaria GM n.․․ 2.037, de 15 de dezembro de 1999. NR 21 - Trabalhos a Céu Aberto. Brasília-DF, 1999.

CAMPOS, Renata Moreira; FARIAS, Glaucea Maciel de; RAMOS, Cristiane da Silva. Satisfação profissional da equipe de enfermagem do SAMU/Natal. Rev. Eletr. Enf. [Internet]. 2009;11(3):647-57. 
COSTA, Elaine Carininy Lopes da; SEPÚLVEDA, Geysa Soares de. Equipamentos de proteção individual: percepção da equipe de enfermagem quanto ao uso. Rev. Enferm UFPI. 2013 Oct-Dec;2(4):72-7.

GOMES, Bonifácio Barbosa; SANTOS, Walquiria Lene dos. Acidentes laborais entre equipe de Atendimento Pré-Hospitalar Móvel (bombeiros/SAMU) com destaque ao risco biológico. Revisa, 2012; 1(1): 40-49 - Jan/Jun 2012.

GUIMARAES, Eliete Albano de Azevedo et al. Percepção de técnicos de enfermagem sobre o uso de equipamentos de proteção individual em um serviço de urgência. Cienc. enferm. [online]. 2011, vol.17, n.3, pp. 113-123.

LÚCIO, Marcelo Guedes; TORRES, Marina Canuto; GUSMÃO, Cristine Maria Pereira. Riscos Ocupacionais do atendimento pré-hospitalar: uma revisão bibliográfica. Interfaces Científicas - Saúde e Ambiente. Aracaju, V. 1, N. 3, p. 6977, jun. 2013.

MARTINS, Pedro Paulo Scremin; PRADO, Maria Lenise do. Enfermagem e serviços de Atendimento Pré-Hospitalar: descaminhos e perspectivas. Rev Bras de Enf., 2003; 56: 71-5.

OENNING, Nágila Soares Xavier et al. Assunção de riscos ocupacionais no serviço de atendimento móvel de urgência (SAMU). Rev enferm UFPE [online]. 2012 Feb;6(2):346-52.

OLIVEIRA, Adriana Cristina; LOPES, Aline Cristine Souza; PAIVA, Maria Henriqueta Rocha Siqueira. Acidentes ocupacionais por exposição a material biológico entre a equipe multiprofissional do Atendimento Pré-Hospitalar. Rev. esc. enferm. USP [online]. 2009, vol.43, n.3, pp. 677-683.

PEREIRA, Waleska Antunes da Porciúncula; LIMA, Maria Alice Dias da Silva. O trabalho em equipe no atendimento pré-hospitalar à vítima de acidente de trânsito. Rev. esc. enferm. USP [online]. 2009, vol.43, n.2, pp. 320-327. 
PRODANOV, Cleber Cristiano; FREITAS, Ernani Cesar de. Metodologia do trabalho científico: métodos e técnicas da pesquisa e do trabalho acadêmico. 2. ed. Novo Hamburgo: Feevale, 2013

SANTANA, Júlio César Batista et al. Desafios enfrentados pelos técnicos de enfermagem que atuam em um serviço de atendimento móvel de urgência. Rev. Enfermagem Revista. v. 15. n 01. Jan/Abr. 2012.

SÃO PAULO. Secretaria de Estado de Saúde. Rede Brasileira de Cooperação em Emergências. Manual do curso de regulação médica. São Paulo, 2001.

SILVA, Andréa Rosane Souza et al. Meio Ambiente hospitalar e o risco ocupacional da equipe de enfermagem: uma revisão integrativa. Cadernos de Graduação Ciências Biológicas e da Saúde Facipe. Recife, v. 1, n.1, p. 11-20, agosto 2013a.

SILVA, Izabel Cristina Brito da et al. Estresse em enfermeiros do Serviço de Atendimento Móvel de Urgência (SAMU) de Recife-PE. 17ํ SENPE - Seminário Nacional de Pesquisa em Enfermagem. O Clássico e o Emergente: Desafios da Pesquisa em Enfermagem 03 a 05 de junho de 2013b. Natal/RN.

TIPPLE, Anaclara Ferreira Veiga et al. Acidente com material biológico no Atendimento Pré-Hospitalar móvel: realidade para trabalhadores da saúde e não saúde. Rev. bras. enferm.[online]. 2013, vol.66, n.3, pp. 378-384.

ZAPPAROLI, Amanda dos Santos; MARZIALE, Maria Helena Palucci. Risco ocupacional em unidades de Suporte Básico e Avançado de Vida em Emergências. Rev. bras. enferm.[online]. 2006, vol.59, n.1, pp. 41-46.

Enviado: Dezembro, 2020.

Aprovado: Dezembro, 2020. 